International Journal of Child, Youth and Family Studies (2014) 5(4): 588-608

In Harm's Way: A Special Issue on the Impacts and Costs of Witnessing Intimate

Partner Violence

\title{
BEGINNING TO UNDERSTAND THE ECONOMIC COSTS OF CHILDREN'S EXPOSURE TO INTIMATE PARTNER VIOLENCE
}

\section{Martin A. Andresen and Shannon J. Linning}

\begin{abstract}
Intimate partner violence comprises 37\% of violent crime in Canada, imposing significant economic costs on society. Childhood exposure to intimate partner violence is a well-documented phenomenon, but the resulting costs are less understood. Some research has found that children exposed to intimate partner violence are at a greater risk of developing health and behavioural problems that potentially impact these children as well as society as a whole. However, there is no known estimate of the economic costs of this exposure to intimate partner violence. In this paper, we develop a simple model to estimate these costs. We estimate that each year there are approximately 125,000 new children exposed to intimate partner violence generating a yearly economic cost to society of $\$ 759$ million for that one cohort of children in Canada. Over a period of 10 years, this one cohort would impose an economic cost of $\$ 7.0$ billion, and this is substantially underestimated because it does not include the new sets of children exposed to intimate partner violence each year. As such, the potential for societal economic cost savings resulting from the prevention of intimate partner violence is significant.
\end{abstract}

Keywords: intimate partner violence, childhood exposure, economic costs

Martin A. Andresen, Ph.D. is an Associate Professor in the School of Criminology at Simon Fraser University, 8888 University Drive, Burnaby, British Columbia, Canada V5A 1S6. E-mail: andresen@sfu.ca

Shannon J. Linning is a graduate student in the School of Criminology at Simon Fraser University, 8888 University Drive, Burnaby, British Columbia, Canada V5A 1S6.

E-mail: sj16@sfu.ca 
International Journal of Child, Youth and Family Studies (2014) 5(4): 588-608

In Harm's Way: A Special Issue on the Impacts and Costs of Witnessing Intimate Partner Violence

Intimate partner violence (IPV) compromises approximately $30 \%$ of all violent crime reported to the police in Canada (Sinha, 2012). However, it is well known that not all crime is reported to the police. With the reporting rates to the police for IPV and violent crime as a whole being $22 \%$ and $29 \%$ respectively, IPV is estimated to be $37 \%$ of all violent crime (Brennan, 2011; Brennan \& Dauvergne, 2011). Because this significant proportion of violence is based on IPV, this is not an issue that can be ignored if (violent) victimization is considered a concern in our society. As with any form of crime, the costs of IPV can be estimated. These costs consider both the direct costs (medical services, counselling, police and criminal justice services, etc.) and indirect costs (decreases in productivity, loss in the quality of life (pain and suffering), etc.). In this context, Zhang, Hoddenbagh, McDonald, and Scrim (2012) estimated that the total economic impact of IPV in 2009 for Canada was $\$ 7.4$ billion, with costs borne by the victims comprising over $80 \%$ of that figure.

Absent from this estimate and others (e.g., Reeves \& O’Leary-Kelly, 2007; Rivara et al., 2007; Varcoe et al., 2011) are the economic costs borne by the children exposed to IPV. Of course, in these studies the authors are investigating the impact of IPV on the direct victims of IPV such that the economic costs of exposure to IPV are beyond the scope of their research. In fact, we are unaware of any studies that investigate the economic effects on these children or on the health, social, and justice agencies that respond to these children. There are many costing studies that investigate the effects of child maltreatment - see Brown, Fang, and Florence (2011) for a systematic review - but none that identify the independent effect of children's exposure to IPV.

In this study, we make a first cut at such an economic cost estimation. We consider: the effects of children's exposure to IPV, some measurable and others not; the number of new annual exposures of children to IPV; and the ultimate economic costs of children's exposure to IPV considering a number of different contexts with sensitivity analyses.

\section{Effects of Children's Exposure to IPV}

The effects of children's exposure to IPV are many and varied. Children's exposure to IPV has been found to be associated with neurological disorders, physical health outcomes, mental health and substance use outcomes, conduct and behavioural outcomes, delinquency, crime and victimization, and academic and employment outcomes (Anda et al., 2006; Anda, Tietjen, Schulman, Felitti, \& Croft, 2010; Ramiro, Madrid, \& Brown, 2010). The difficulty, however, in assessing the economic costs of these outcomes is the need for: (a) the number of new children exposed to IPV annually; (b) base rates of these outcomes to avoid double-counting; (c) the increase factor (risk of these outcomes resulting from children's exposure to IPV); and (d) costs associated with these various outcomes. If any one of these four items is missing, the economic costs associated with them cannot be estimated. This is a limitation we encountered for many of the individual outcomes listed in the outcome categories above. 
International Journal of Child, Youth and Family Studies (2014) 5(4): 588-608

In Harm's Way: A Special Issue on the Impacts and Costs of Witnessing Intimate Partner Violence

The number of new children exposed to IPV annually is estimated below, and despite the lack of data, we were able to obtain all three of the latter items for our estimates. Data used in these estimates are drawn from many countries, but Canadian data are used where possible. The following individual outcomes are considered for oneyear costs: sleep disturbances, asthma, frequent headaches, smoking, alcohol abuse, driving under the influence, illicit substance abuse, early pregnancy, unintended pregnancy, attempted suicide, conduct disorder, referral to a speech pathologist, and living below or at poverty.

\section{Sleep Disturbances}

Sleep disturbance is a more general term that captures not only insomnia, but also the phenomena of having difficulty getting to sleep and staying asleep, as well as feeling tired after what should be a good night's sleep (Anda et al., 2006). And the literature on the effect on children exposed to IPV is an increase in its prevalence by a factor of $20 \%$, 1.2. The base rate for sleep disturbances had wide variation, ranging from: $35 \%$ to $40 \%$ (Hossain \& Shapiro, 2002); 30\% to 32\% (Rosekind et al., 2010); 30\% to 48\% (Ohayon, 2002); and 33\% (Daley, Morin, LeBlanc, Gregoire, \& Savard, 2009). In order to err on being conservative, we use $30 \%$ in the calculations below.

With regard to the economic costs of sleep disturbances, there are equally wideranging estimates. However, this is primarily due to what is included in the economic costs: direct costs (medications and health care services) and other costs (vehicle collisions attributed to sleep disturbances). Though there are a number of these studies available (see, for example, Hossain \& Shapiro 2002, Rosekind et al., 2010, and Daley et al., 2009), we used the estimates of Hillman, Murphy, Antic, and Pezzullo, (2006) because they were the most inclusive, considering direct health costs, work-related injuries, vehicle collisions, and productivity loss for one year. The Hillman et al. (2006) annual estimate is national (Australian), so this was transformed into a per person cost. Per person here, and in all subsequent calculations, refers only to those people who are involved in the outcome - sleep disturbances in this case. This is because we are not concerned with the cost that each person has to pay - using the total (working) population as the denominator - but rather the average cost imposed on society by the individual directly involved in the outcome. Transforming this figure into 2013 Canadian dollars gives us \$9,490 per person per year; all subsequent dollar figures mentioned are 2013 Canadian dollars.

\section{Asthma}

According to Subramanian, Ackerson, Subramanyam, and Wright (2007), the effect on children exposed to IPV on asthma is an increase in its prevalence by a factor of $15 \%$ to $19 \%, 1.15$ to 1.19 . In our calculations below, we use 1.15 to be conservative. The base rate for asthma varies by the age of the individual and is greater for children than adults. However, there is very little variation across studies (Barnett \& Nurmagambetov, 2011; Centers for Disease Control and Prevention, 2011). Generally speaking, the base 
International Journal of Child, Youth and Family Studies (2014) 5(4): 588-608

In Harm's Way: A Special Issue on the Impacts and Costs of Witnessing Intimate Partner Violence

rate for asthma in the general population ranges from $6.9 \%$ to $9.6 \%$. We use $7 \%$ as a conservative estimate. The cost of asthma is based on work undertaken in the United States (Barnett \& Nurmagambetov, 2011; Centers for Disease Control and Prevention, 2011); that is, $\$ 3,995$ per person per year.

\section{Frequent Headaches}

As identified by Anda et al. (2010), children exposed to IPV have an increase in frequent headaches by a factor of $30 \%, 1.3$. The prevalence of (being troubled by) frequent headaches depends upon the specific research within each study. Those studies that investigate migraines identify prevalence rates of: 11\% (Lipton, Stewart, \& Scher, 2001); 9.6\% to 23.2\% (Berg \& Stovner, 2005); and 17\% (Pradalier et al., 2004). However, the occurrence of frequent headaches is a more inclusive outcome with a prevalence of 15.6\% (Anda et al., 2010, in a review) and 29\% to 77\% (Berg \& Stovner, 2005). Consequently, we use $15 \%$ as a conservative estimate of the prevalence of frequent headaches. Oleson, Gustavsson, Svensson, Wittchen, and Jonsson (2012) found the per person per year cost of headaches to be $\$ 410$.

\section{Smoking}

Children exposed to IPV have an increased rate of smoking by a factor of $30 \%$, 1.3. The prevalence of smoking in the United States and the United Kingdom is just over 20\% (Scarborough et al., 2011; Centers for Disease Control and Prevention, 2006), a figure that has remained constant since at least the early 2000s. Using data from Health Canada and Statistics Canada, smoking prevalence in Canada was 17.3\% in 2011 for the general population, but $23.8 \%$ and $21.5 \%$ for the populations mostly under consideration here, 25 to 34 years and 20 to 24 years respectively (Reid, Hammond, Burkhalter, Rynard, \& Ahmed, 2013). We use a 20\% prevalence rate for the base rate in the calculations below to err on the conservative side. The Centers for Disease Control and Prevention (2002, 2008) have estimated the health-related and economic costs attributed to smoking to be $\$ 6,500$ per person per year.

\section{Alcohol Abuse}

Alcohol use by children who are exposed to IPV is at a rate $70 \%$ greater than the general population, 1.7 (Ramiro et al., 2010), whereas alcohol abuse through adulthood (defined as a self-proclaimed alcoholic) by children who are exposed to IPV is $100 \%$ greater than the general population, 2.0 (Anda et al., 2006). Considering the estimates for the prevalence of alcohol use that is considered high, defined below, we use the $70 \%$ increase in prevalence to err on the side of conservative estimates. The prevalence rates for a high level of alcohol use (exceeding government benchmarks for heavy drinking) range from: $20 \%$ and $15 \%$ of men and women respectively (Scarborough et al., 2011); 12.5\% (Lee \& Forsythe, 2011); and 8.5\% (Hasin, Stinson, Ogburn, \& Grant, 2007). We use $8.5 \%$ in the calculations below. The economic cost of alcohol abuse, based on Bouchery, Harwood, Sacks, Simon, and Brewer (2011) and Sacks et al. (2013), is \$5,951 
International Journal of Child, Youth and Family Studies (2014) 5(4): 588-608

In Harm's Way: A Special Issue on the Impacts and Costs of Witnessing Intimate Partner Violence

per person per year: These costs include lost productivity (72.2\%), health care costs (11\%), criminal justice costs (9.4\%), and other costs (7.5\%).

\section{Driving Under the Influence of Alcohol}

Driving under the influence of alcohol is at an increased prevalence of 30\%, 1.3, by children who are exposed to IPV (Anda et al., 2006). Caetano and McGrath (2004) found the prevalence of driving under the influence of alcohol and/or drugs to be just over $20 \%$. We use $20 \%$ in all the calculations below. Though Bouchery et al. (2011) estimate the economic cost of deaths due to driving under the influence, more inclusive estimates that include the costs of vehicle collisions (including lost labour market productivity, property damage, medical expenses, and travel delay) are provided by Blincoe et al. (2002) and Moore, Harrison, Young, and Ochshorn (2008). Based on these latter national level estimates, the economic cost per person per year of driving under the influence is $\$ 2,315$.

\section{Illicit Substance Abuse}

Illicit substance abuse has a relatively low prevalence rate in the general population; children exposed to IPV have a 70\% increased prevalence, 1.7 (Ramiro et al. 2010). Compton, Thomas, Stinson, and Grant (2007) estimate the base rate of illicit substance abuse to range from $1.4 \%$ to $2.0 \%$. We use $1.4 \%$ in the calculations below. Though the prevalence of illicit substance abuse is low, the costs associated with that substance abuse are substantial, considering costs such as health care, productivity losses, criminal justice costs, and other related costs that are associated with illicit substance abuse. Based on the per capita costs of illicit substance abuse (productivity losses, medical costs, law enforcement costs, and other costs) estimated by Rehm et al. (2006), the estimated cost per illicit substance abuser per year is $\$ 22,886$.

\section{Early Pregnancy}

Early pregnancy, defined as a pregnancy at 18 years of age or younger, is twice as prevalent within children (females) exposed to IPV (Ramiro et al., 2010). The prevalence of early pregnancy has been estimated as 41.9 per 1,000 females in 2006, up from 40.5 per 1,000 females in 2005 (Martin et al., 2008). We use 4\% (40 per 1,000 females) in the calculations below. The economic cost of early pregnancy is estimated at $\$ 2,205$ per person per year, based on lower earning/productivity of the teen parents and their children, increased use of social services, and increased prison costs (Hoffman \& Maynard, 2008).

\section{Unintended Pregnancy}

Children (females) who are exposed to IPV have a 50\% increased prevalence, 1.5, in unintended pregnancies among adult women (Ramiro et al., 2010). Both Trussel (2007) and Finer and Zolna (2011) have found that the base rate of unintended 
International Journal of Child, Youth and Family Studies (2014) 5(4): 588-608

In Harm's Way: A Special Issue on the Impacts and Costs of Witnessing Intimate Partner Violence

pregnancies is approximately 50\%. The economic costs of unintended pregnancies stem from the births themselves (medical costs of child delivery), terminated pregnancies, and stillbirths (Trussel, 2007; Sonfield, Kost, Gold, \& Finer, 2011). We use the more conservative estimate of Trussel (2007), less than 50\% of the more comprehensive estimate of Sonfield et al. (2011), estimating that the economic cost per person per year is $\$ 1,998$.

\section{Attempted Suicide}

Children exposed to IPV have an $80 \%$ greater prevalence of suicide attempts, 1.8, than in the general population (Ramiro et al., 2010). The base rate for suicide attempts has been shown to be $4.6 \%$ (Kessler, Borges, \& Walters, 1999) and ranging from 3\% to $5 \%$ (Weissman et al., 1999). We consider the prevalence of $4 \%$. The costs associated with attempted suicides vary quite widely depending on the injuries that result from the attempt. Yang and Lester (2007) found that the range of economic costs for attempted suicide was approximately $\$ 2,000$ to $\$ 68,000$ (2005 USD). The average cost has been identified as $\$ 12,570$ and $\$ 13,690$, so we base our calculations on $\$ 12,500$ leading to a per person per year cost of $\$ 17,373$.

\section{Conduct Disorder}

Conduct disorders are defined as behaviours such as bullying, threatening or intimidating others, being absent from school often, or lying to get something or avoid having to do something (Foster \& Jones, 2005). Children exposed to IPV in the United States have been found to have a 78 percent greater prevalence, 1.78, of conduct disorders than the general population (Foster \& Jones, 2005). However, research in Canada estimates that children aged 6 to 11 years exposed to IPV have a 124\% greater prevalence, 2.24, of highly aggressive behaviour (Hotton, 2003); whereas children aged 4 to 11 years have a $133 \%$ to $197 \%$ greater prevalence, 2.33 to 2.97 , for hyperactivity, indirect aggression, and physical aggression (Dauvergne \& Johnson, 2001). As such, we use the increase risk factor of 2.5, the average of the greater prevalence found in the Canadian context. Henggeler and Sheidow (2003) found that the prevalence of conduct disorder ranges from $1 \%$ to $6 \%$. We use $3 \%$ in the calculations below. Based on economic costs in criminal justice, child welfare, special education, and mental health, Foster and Jones (2005) estimate the economic cost of conduct disorder to be \$19,115 per person per year.

\section{Referral to a Speech Pathologist}

Children exposed to IPV have 7.5 times the referral rate to school-based speech pathologists than the general population (Kernic et al., 2002). According to Aron and Loprest (2012), 22\% of students possess a speech or language impairment. However, such a base rate is not realistic. Statistically speaking, we would only expect $2.5 \%$ of the population to have true speech or language impairment, unless language impairment included learning English as another language and impairment was defined as functional 
International Journal of Child, Youth and Family Studies (2014) 5(4): 588-608

In Harm's Way: A Special Issue on the Impacts and Costs of Witnessing Intimate Partner Violence

within a particular society - this is, based on $2.5 \%$ of the population in a normal distribution being two standard deviations to the left of the average. However, according to the 2007 American Community Survey conducted by the United States Census Bureau, over $94 \%$ of the United States is English speaking. And in Canada, according to the 2011 Census of population, 86\% of the population is English speaking ${ }^{1}$. Considering this, and the fact that the factor identified by Kernic and colleagues (2002) referred to referrals to a school-based speech pathologist, we consider $10 \%$ of the Aron and Loprest (2012) prevalence rate, $2.2 \%$. This number also falls within what would be expected from a statistical perspective (2.5\%). The economic costs of a school-based speech pathologist were estimated to be just over $\$ 10,000$ for 2000 in the United States (Aron \& Loprest, 2012). As such, the per person per year cost is $\$ 19,115$.

\section{Below or at Poverty}

Lastly, children exposed to IPV as children are twice as likely to fall below the poverty line as the general population when they become adults (Zielinski, 2009). The studies investigating the prevalence of poverty, and specifically those that consider children living in poverty, have variances in prevalence that are based on the definition of poverty itself. The most recent study (in the United States) that investigates this prevalence (Adamson, Bradshaw, Hoelscher, \& Richardson, 2007) found that 22\% of children live in poverty. However, the figure that is of concern here is the percentage of the population living in poverty, not just children. Though estimates of such a statistic are readily available in the United States, there is no government-sanctioned calculation for those who live below the poverty line. Consequently, there are many estimates of those living in poverty in Canada, ranging from 10\% to 20\% (Canada Without Poverty, 2014). As such, we use the median value of $15 \%$ in our calculations below; this value, incidentally, corresponds with the percentage in the United States. The economic costs of witnessing IPV in childhood are based on subsequent adult income, participation in crime, and poor health (Holzer, Whitmore Schanzenbach, Duncan, \& Ludwig, 2008) ${ }^{2}$. The per person per year economic cost of childhood poverty is estimated at $\$ 8,108$.

\section{Summary and Exclusions}

Though there are 13 outcomes considered in the economic costs of children's exposure to IPV, there are a number of outcomes that have been identified but were difficult to implement in the analysis below. The prevalence of being absent or suspended from school, receiving lower grades, or having lower reading levels were not included because of difficulties in estimating the costs and prevalence associated with this outcome; also, because these outcomes are likely components in other outcomes, such as conduct behaviours, their exclusion avoids the potential double counting of costs.

\footnotetext{
${ }^{1}$ http://www12.statcan.gc.ca/census-recensement/2011/dp-pd/hlt-fst/lang/index-eng.cfm?Lang=E

${ }^{2}$ Ideally, we would obtain the necessary data for these factors individually. However, the necessary data are not available to us so this composite measure must be used instead. As such, this estimate should be considered an underestimate of the true cost of being at or below poverty.
} 
International Journal of Child, Youth and Family Studies (2014) 5(4): 588-608

In Harm's Way: A Special Issue on the Impacts and Costs of Witnessing Intimate Partner Violence

A notable absence is also an estimate of the economic costs imposed from criminal activity. The prevalence and economic costs of crime are well documented in the criminological and economic literatures (Cohen, 1998; Cohen \& Piquero, 2009; Cohen, Rust, Steen, \& Tidd, 2004; Cohen, Piquero, \& Jennings, 2010; Craig, Schumann, Petrunka, Khan, \& Peters, 2011; DeLisi \& Gatling, 2003; Park, 2010; Zhang et al., 2012). However, these costs are at least partially considered in the outcomes of illicit substance abuse, conduct disorder, and living below or at poverty. As such, in an effort to avoid the double counting of the economic costs of delinquency, these costs are not explicitly included in the analysis below. Consequently, this maintains the conservative nature of the subsequent estimates because some economic costs of criminal delinquency are most certainly excluded; one does not have to engage in illicit substance abuse, conduct disorders, or live in poverty to commit criminal events.

Similarly, children who witness IPV have a higher prevalence of adolescent alcohol abuse and illicit substance abuse. Though these could have been included in the calculations below, they are not in order to avoid double counting and to generate more conservative estimates - these costs would be partially included within illicit substance abuse, conduct disorder, and living below or at poverty already. Consequently, all of the economic costs present below in their various contexts must be considered underestimates of the true economic costs associate with children's exposure to IPV.

Table 1 presents a summary table of all the outcomes from children exposed to IPV used in the economic cost calculations below, along with the base rates, IPV factors, and economic costs per person per year. Clearly evident from Table 1 is that the marginal costs of each outcome, with the exception of illicit substance abuse, are most often rather low. Consequently, an important factor in the calculation of any economic costs is the number of children exposed to IPV.

Table 1. Summary of outcomes for children exposed to IPV in cost calculations

\begin{tabular}{|l|c|c|c|}
\hline IPV Outcome & Base Rate & IPV Factor & $\begin{array}{c}\text { Economic Cost per person per } \\
\text { year, 2013 CDN\$ }\end{array}$ \\
\hline Sleep disturbance & 0.30 & 1.2 & 9,490 \\
\hline Asthma & 0.07 & 1.15 & 3,995 \\
\hline Frequent headaches & 0.15 & 1.3 & 410 \\
\hline Smoking & 0.20 & 1.3 & 6,500 \\
\hline Alcohol use & 0.085 & 1.7 & 5,951 \\
\hline DUI & 0.20 & 1.3 & 2,315 \\
\hline Illicit substance abuse & 0.014 & 1.7 & 22,886 \\
\hline Early pregnancy & 0.04 & 2.0 & 2,205 \\
\hline Unintended pregnancy & 0.5 & 1.5 & 1,998 \\
\hline Attempted suicide & 0.04 & 1.8 & 17,373 \\
\hline Conduct disorder & 0.03 & 2.5 & 19,115 \\
\hline Speech pathologist & 0.022 & 7.5 & 19,115 \\
\hline Child poverty & 0.15 & 2.0 & 8,108 \\
\hline
\end{tabular}


International Journal of Child, Youth and Family Studies (2014) 5(4): 588-608

In Harm's Way: A Special Issue on the Impacts and Costs of Witnessing Intimate

Partner Violence

\section{New Annual Exposures of Children to IPV}

When considering the economic costs of children exposed to IPV, a reliable estimate of the number of children exposed to IPV is critical. As such, we undertake a number of different calculations to ensure consistency and reliability with this estimate. This is important because if there is a lot of variation between the different calculations, one cannot be sure any one of them is reliable. However, if all of the calculations produce similar results, we can be confident in the estimates that are produced.

There are a number of issues that must be considered. First, if reliance is made using official police data, there is a significant degree of under-reporting of IPV. Second, not all situations with IPV are in the potential presence of children. Third, not all children will be aware of any IPV in the household. Fourth, there is a high degree of repeat victimization in the context of IPV that must be considered in order to identify the number of new exposures of children to IPV; this assumes that the "damage is done" after one exposure and we do not want to count the same children twice. And fifth, not all of the outcomes shown in Table 1 will be applicable to all children. In order to make an estimate of the number of children exposed to IPV each year, these issues are considered in three different estimates of the size of this population in Canada; two of these estimations are independent, with the third being related to one of the other estimations.

The first estimation uses police incident data as its base. According to Statistics Canada (2011), the rate of IPV in Canada, 2010, was 363 per 100,000 population. However, as indicated in the repeat victimization literature, the percentage of repeat victims is $42 \%$ in the United Kingdom based on the British Crime Survey (Hanmer, Griffiths, \& Jerwood, 1999), 44\% in Canada and the United States according to the International Crime Victims Survey (van Dijk, 2001), and more than 50\% in Canada, based on an estimate of two or more victimizations per year (Sinha, 2012; Statistics Canada, 2011). Considering the upper bound of $50 \%$ as a conservative estimate of repeat victimization, the new/unique rate of IPV in Canada is 181.5 per 100,000, based on police incident data. However, under-reporting is also a known issue regarding IPV. According to the General Social Survey in Canada, the percentage of IPV incidents reported to the police was 28\% and 22\% in 2004 and 2009, respectively (Mihorean, 2005). This result indicates a reduction in the rate of reporting of IPV to the police, but we split the difference and use a $25 \%$ rate of reporting to the police to be conservative. This results in a final rate of 726 per 100,000, of those aged 15 and older. In 2013 in Canada, there were 29,484,181 persons 15 years or older leading to 214,055 new victims of IPV each year in Canada.

In Canada, 70\% of households are classified as families, that is, places where children may be present (Statistics Canada, 2007), and the average number of children a woman in Canada had in 2011 (the most recent data) was 1.6 children. The first figure reduces the number of potential children exposed to IPV, whereas the second figure increases the number of children exposed to IPV. And finally, according to Johnson 
International Journal of Child, Youth and Family Studies (2014) 5(4): 588-608

In Harm's Way: A Special Issue on the Impacts and Costs of Witnessing Intimate Partner Violence

(1996) based on results from the 1993 Violence Against Women Survey, 40\% of children are exposed to the IPV in their home; this is a lower bound because parents have a tendency to underestimate how much their children are aware of, while others have estimated the exposure of children to IPV to be as high as $60 \%$ to $80 \%$ (Jaffe, Wolfe, \& Wilson, 1990). However, more recent data from the General Social Survey in Canada has shown that this exposure has risen in recent years. According to the most recent and available data, the percentage of children exposed to IPV has risen from $43 \%$ to $52 \%$ (Sinha, 2012).

Consequently, of these 214,055 new victims of IPV each year, 70\% are in familybased households $(149,839)$ with an average of 1.6 children $(239,742$ children potentially exposed), with 52\% of those children actually being exposed to IPV (124,666 new exposures each year). Based on 2013 population data from Statistics Canada, this represents just less than $1.8 \%$ of all Canadian children. Over the course of 18 years, considering childhood to represent the years of 0 through 17 , this indicates that one-third of the population has been exposed to IPV.

The second estimation is more straightforward, based on the number of victims of IPV in any given year. According to Johnson (1996), 3\% of women are victims of IPV in any given year; because of the relative stability of self-reported spousal victimization, we use Johnson's (1996) number (Brennan, 2011; Sinha, 2012). With a 2013 (Canada) female population (15 years or older) of 14,962,543, there are 448,876 victims of IPV in any given year. Considering a 50\% repeat victimization rate, this leads to 224,438 new women victims of IPV in any given year. Multiplying this number by $70 \%$ (family-based households), then 52\% (children exposed to IPV), and then by 1.6 (the average number of children per woman) generates an estimate of 130,713 new children exposed to IPV each year.

For a more direct comparison to Johnson (1996) - the number of police-reported victims of IPV in 2010 (Sinha, 2012) - there were 102,500 victims; this is based on the rate used in the first estimation so it should not be considered an independent estimate. Multiplying this number by 4 (a conservative estimate of under-reporting to the police) leads to 410,000 victims of IPV in 2010,,and 429,229 victims of IPV in 2013 based on a population growth of $4.69 \%$ during those years. Considering the same multiplication factors above, this leads to an estimate of 124,991 new children exposed to IPV each year.

The third estimation, one that is related to the previous estimation, considers the number of children exposed to IPV in 1993: 160,000 (Johnson, 1996). Because this estimate by Johnson (1996) was based on the number of women, it should be multiplied by the growth of women in Canada from 1993 to 2013, 29.1\%. This results in 206,538 children exposed to IPV each year. And considering repeat victimization (50\%) this results in 103,269 new children exposed to IPV each year. However, this number is based on previous estimates of the percentage of children exposed to IPV; this number therefore 
International Journal of Child, Youth and Family Studies (2014) 5(4): 588-608

In Harm's Way: A Special Issue on the Impacts and Costs of Witnessing Intimate Partner Violence

needs to be multiplied by 1.21 to represent the increase in exposure rates leading to 124,883 new children exposed to IPV each year.

Because all three of these estimations generate basically the same result - 125,000 new children exposed to IPV each year - this number is considered robust and used in all the calculations below as the base number of new children exposed to IPV each year. However, certain outcomes from childhood exposure to IPV are restricted to subpopulations within that 125,000 . For example, unintended pregnancies can only be attributed to the female population, approximately $48 \%$ of those between the ages of 0 and 17, and early pregnancies are defined as females who become pregnant at 18 years or younger. Because the 125,000 number is based on those with a maximum age of 17 and this literature considers 15 as the age of potential pregnancies, this leaves females between and including the ages of 15 and 17. These are the outcomes in which pure biology plays a role. However, many of these outcomes would not become apparent until the later years of childhood: It is unlikely that smoking, alcohol and drug use, and suicide, for example, would become issues before 12 years of age. Additionally, conduct behaviour and referrals to school-based speech pathologists are outcomes with costs borne in the school system, the former for those aged 11 to 17 years and the latter for those 5 to 17 years of age.

Consequently, all of the economic costs calculated below consider the appropriate female population and school age population. Also, some economic costs consider age appropriate ranges for all outcomes, reducing the 125,000 number to the appropriate number. This begins with only those between the ages of 12 and 17 years being able to impose societal costs from these outcomes. These can be seen in Table 2 . Though some research has indicated that long-term memory begins as early as age 1 (Cromie, 2002, based on the research undertaken by Jerome Kagan), most research indicates that 3 years of age is when long-term memory begins to be more prominent (Bauer \& Larkina, 2013). Childhood amnesia is still apparent at this age, and until 7 or 8 years, but the exposure to IPV may be considered significant enough to be retained by children as young as 3 years old. As such, when age restrictions are considered, children aged 0 to 2 are excluded.

\section{Table 2. Percentages of age ranges and females}

\begin{tabular}{|l|l|}
\hline Females, 15 to 17 & $8.8 \%$ \\
\hline All, 12 to 17 & $34.5 \%$ \\
\hline All, 11 to 17 & $39.8 \%$ \\
\hline All, 10 to 17 & $45.1 \%$ \\
\hline All, 9 to 17 & $50.4 \%$ \\
\hline All, 8 to 17 & $55.7 \%$ \\
\hline All, 7 to 17 & $61.1 \%$ \\
\hline All, 6 to 17 & $66.6 \%$ \\
\hline All, 5 to 17 & $72.3 \%$ \\
\hline All, 4 to 17 & $77.9 \%$ \\
\hline All, 3 to 17 & $83.5 \%$ \\
\hline
\end{tabular}


International Journal of Child, Youth and Family Studies (2014) 5(4): 588-608

In Harm's Way: A Special Issue on the Impacts and Costs of Witnessing Intimate Partner Violence

\section{Economic Costs of Children's Exposure to IPV}

With the number of new children exposed to IPV, base rates of outcomes, the effect of exposure to IPV on those base rates, and the associated costs of the outcomes, the economic costs of children's exposure to IPV can be estimated. In our calculations, we use a simple model. The base rate of any given outcome applies to the general population so we do not want to consider this rate for our cost calculations. Rather, we want to consider the additional cases of each outcome resulting from childhood exposure to IPV. For example, if the base rate is $5 \%$ and the effect of childhood exposure to IPV is $50 \%$ (an increase factor of 1.5 ), we do not use $7.5 \%$ as our prevalence rate but $2.5 \%$ because the initial $5 \%$ are expected to occur regardless. This $2.5 \%$ is then multiplied by the appropriate population and marginal cost in order to obtain the annual expected cost of childhood exposure to IPV for that particular outcome. Total costs are obtained by simply adding all of the marginal costs. All necessary data for these calculations are contained within Tables 1 and 2, but our spreadsheet for the values reported below are available to the interested reader. Though this basic modelling approach may be considered simplistic, in other research the lead author found that simple costing models have proven to generate far more realistic results than more complex models, when compared to actual data (see, for example, the discussion in Andresen \& Jozaghi, 2012, p. 3533).

Table 3. Economic costs, by issue, total dollars, and percentage of total

\begin{tabular}{lrr}
\hline Issue & $\begin{array}{c}\text { Total Annual Cost per Issue } \\
\text { (Millions 2013 CDN\$) }\end{array}$ & $\begin{array}{c}\text { Percentage } \\
\text { of Total }\end{array}$ \\
\hline Sleep Disturbance & 71.18 & 0.09 \\
Asthma & 5.24 & 0.01 \\
Frequent Headaches & 2.31 & 0.00 \\
Smoking & 48.75 & 0.06 \\
Alcohol Use & 44.26 & 0.06 \\
DUI & 17.36 & 0.02 \\
Illicit Substance Use & 28.04 & 0.04 \\
Early Pregnancy & 0.97 & 0.00 \\
Unintended Pregnancy & 30.4 & 0.04 \\
Attempted Suicide & 69.49 & 0.09 \\
Conduct Disorder & 42.13 & 0.06 \\
Referred to Speech Pathologist & 246.91 & 0.33 \\
Below Poverty & 152.03 & 0.20 \\
\hline & & \\
Total & 759 & \\
\hline
\end{tabular}


International Journal of Child, Youth and Family Studies (2014) 5(4): 588-608

In Harm's Way: A Special Issue on the Impacts and Costs of Witnessing Intimate Partner Violence

The first estimated economic cost of children exposed to IPV restricts pregnancy to the appropriate female population and all children to the appropriate school ages, generating a yearly economic cost to society of $\$ 759$ million for one cohort of children exposed to IPV (see Table 3$)^{3}$. This figure should be considered an upper bound for our conservative estimate of the annual economic cost of children exposed to IPV.

Discounted at $2 \%$ per year (average inflation over the past 10 years has been $1.7 \%$ ), this results in a 10-year cost of one cohort of children exposed to IPV at \$7.0 billion; this number does not include any growth in the population and is, therefore, an underestimate from that perspective.

When the age range on the non-biological and school-based outcomes is restricted to those aged 12 to 17 years (34.5\% of the 125,000), a yearly economic cost to society of $\$ 472$ million is estimated for one cohort of children exposed to IPV. This results in a 10year cost of one cohort of children exposed to IPV at $\$ 4.3$ billion, again not considering population growth. These figures should be considered lower bounds of the true cost of children exposed to IPV.

When the age range on the non-biological and school-based outcomes is restricted to those aged 3 to 17 years $(83.5 \%$ of the 125,000$)$, in order to account for memory retention of children at very young ages, a yearly economic cost to society of $\$ 687$ million is estimated for one cohort of children exposed to IPV, with a \$6.3 billion 10-year cost of one cohort of children exposed to IPV.

These 10-year economic cost estimates are also unrealistically low. If we consider 2013 the base year and calculate the annual economic cost to society considering the age range of 12 to 17 years, the following year there will be an entirely new cohort of children exposed to IPV contributing to the economic costs. Consequently, over a 10-year period the actual economic costs of children exposed to IPV is far greater. Considering these additional economic costs, but restricting subsequent cohorts of children exposed to IPV to fewer years in the calculation $(9,8,7$, and so on) the 10-year cost of children exposed to IPV becomes $\$ 26.4$ billion. Subsequent calculations may be undertaken to consider an entire generation of children exposed to IPV, a full 17 years, but it should be clear at this point that the economic costs of children being exposed to IPV are significant. Considered in conjunction with the economic costs of IPV on the direct victims, the costs to our society from this violence are a detriment to our social welfare.

\section{Limitations}

Though the estimates provided above are instructive as a first estimate of the costs associated with children exposed to IPV, there are a number of limitations with the current analysis that must be considered. First, data are not available for all of the outcomes associated with childhood exposure to IPV. Consequently, the estimates here

3 The Percentage of Total column must be treated with caution because we were not able to include all possible issues related to children being exposed to IPV. These numbers are provided to show the relative contribution of each issue in the current context. As future research is able to include more issues related to children being exposed to IPV, these percentages will, no doubt, change. 
International Journal of Child, Youth and Family Studies (2014) 5(4): 588-608

In Harm's Way: A Special Issue on the Impacts and Costs of Witnessing Intimate Partner Violence

may be considered underestimates. Second, though Canadian data were used when available, international studies were used in many cases. Most of these, however, were based in the United States and can be assumed to be similar to Canada, but this is not necessarily the case. Third, and the most significant, is that our estimates are not based on a longitudinal study comparing outcomes of children exposed to IPV and children not exposed to IPV. We attempted to mimic such a methodology by only considering the additional number of people in the general population who would be associated with the various outcomes because of exposure to IPV, but we cannot be sure that our estimates are representative. However, we are confident that our estimates are a good starting point for understanding the costs associated with children exposed to IPV. Using conservative statistics whenever possible, we have demonstrated that the costs borne by society because of children exposed to IPV are significant. Also, with the estimated cost of children witnessing IPV being just over 11\% of IPV, relative to Zhang et al. (2012), our estimate is credible because not all children witness actual IPV victimization and the outcomes investigated here are probabilistic whereas the estimated cost of IPV is from actual victimization. Hopefully, our research will stimulate others to replicate and extend our work. These extensions may be in the context of more sophisticated modelling strategies to investigate their utility or, potentially, through longitudinally-based research.

\section{Conclusion}

Interpersonal violence imposes significant costs to our society. These costs are borne by the direct victims of this violence (the relationship partner) as well as by any children who are involved. This research study has estimated the cost to society from children's exposure to that interpersonal violence. At a minimum that societal economic cost is \$472 million per year, but this estimate does not consider many of the outcomes of exposure to IPV that do not have data available in terms of prevalence or cost.

Additionally, if one considers that most individuals spend more of their life beyond the age of 17 years, the societal economic cost of children's exposure to IPV is \$759 million each year. The literature on the intergenerational transmission of IPV has not generated any conclusive risk factors we are aware of (see Kwong, Bartholomew, Henderson, \& Trinke, 2003), and thus was not included in our earlier cost calculations. However, taking even a conservative 5\% of the economic costs of IPV (based on Zhang et al., 2012) resulting from the direct victims of IPV attributable to intergenerational transmission would cause the societal economic cost of children's exposure to IPV to soar and to easily exceed \$1 billion each year. As such, the potential for societal economic cost savings resulting from the prevention of IPV is significant. 
International Journal of Child, Youth and Family Studies (2014) 5(4): 588-608

In Harm's Way: A Special Issue on the Impacts and Costs of Witnessing Intimate

Partner Violence

\section{References}

Adamson, P., Bradshaw, J., Hoelscher, P., \& Richardson, D. (2007). Child poverty in perspective: An overview of child well-being in rich countries. Florence, Italy: UNICEF Innocenti Research Centre.

Anda, R. F., Feletti, V. J., Bremner, J. D., Walker, J. D., Whitfield, C., Perry, B. D., Dube, S. R., \& Giles, W. H. (2006). The enduring effects of abuse and related adverse experiences in childhood. European Archives of Psychiatry and Clinical Neuroscience, 256(3), 174-186. http://dx.doi.org/10.1007/s00406-005-0624-4

Anda, R. F., Tietjen, G., Schulman, E., Felitti, V. J., \& Croft, J. (2010). Adverse childhood experiences and frequent headaches in adults. Headache: The Journal of Head and Face Pain, 50(9), 1473-1481. http://dx.doi.org/10.1111/j.1526-4610.2010.01756.x

Andresen, M. A., \& Jozaghi, E. (2012). The point of diminishing returns: An examination of expanding Vancouver's Insite. Urban Studies, 49(16), 3531-3544. http://dx.doi.org/10.1177/0042098012443865

Aron, L., \& Loprest, P. (2012). Disability and the education system. The Future of Children, 22(1), 97-122. http://dx.doi.org/10.1353/foc.2012.0007

Barnett, S. B., \& Nurmagambetov, T. A. (2011). Costs of asthma in the United States: 2002-2007. Journal of Allergy and Clinical Immunology, 127(1), 145-152. http://dx.doi.org/10.1016/j.jaci.2010.10.020

Bauer, P. J., \& Larkina, M. (2013). The onset of childhood amnesia in childhood: A prospective investigation of the course and determinants of forgetting of earlylife events. Memory, in press.

Berg, J., \& Stovner, L. J. (2005). Cost of migraine and other headaches in Europe. European Journal of Neurology, 12(1), 59-62. http://dx.doi.org/10.1111/j.1468-1331.2005.01192.x

Blincoe, L. J., Seay, A., Zaloshnja, E., Miller, T., Romano, E., Luchter, S., \& Spicer, R. (2002). The economic impact of motor vehicle crashes, 2000 (No. HS-809 446). Washington, DC: US Department of Transportation, National Highway Traffic Safety Administration.

Bouchery, E. E., Harwood, H. J., Sacks, J. J., Simon, C. J., \& Brewer, R. D. (2011). Economic costs of excessive alcohol consumption in the U.S., 2006. American Journal of Preventive Medicine, 41(5), 516-524. http://dx.doi.org/10.1016/s0749-3797(11)00692-1

Brennan, S. (2011). Self-reported spousal violence, 2009. In Family violence in Canada: A statistical profile. Ottawa, ON: Statistics Canada. 
International Journal of Child, Youth and Family Studies (2014) 5(4): 588-608

In Harm's Way: A Special Issue on the Impacts and Costs of Witnessing Intimate

Partner Violence

Brennan, S., \& Dauvergne, M. (2011). Police-reported crime statistics in Canada, 2010. Ottawa, ON: Statistics Canada.

Brown, D., Fang, X., \& Florence, C. S. (2011). Medical costs attributable to child maltreatment: A systematic review of short- and long-term effects. American Journal of Preventive Medicine, 41(6), 627-635. http://dx.doi.org/10.1016/j.amepre.2011.08.013

Caetano, R., \& McGrath, C. (2005). Driving under the influence (DUI) among US ethnic groups. Accident Analysis \& Prevention, 37(2), 217-224. http://dx.doi.org/10.1016/j.aap.2004.07.004

Canada Without Poverty. (2014). Poverty: Canada Without Poverty. Retrieved August 9, 2014, from http://www.cwp-csp.ca/poverty/

Centers for Disease Control and Prevention. (2002). Annual smoking-attributable mortality, years of potential life lost, and economic costs - United States, 19951999. Morbidity and Mortality Weekly Report, 51(14), 300-303.

Centers for Disease Control and Prevention. (2006). Cigarette smoking among adults United States, 2006. Morbidity and Mortality Weekly Report, 56(44), 1157-1161.

Centers for Disease Control and Prevention. (2008). Smoking-attributable mortality, years of potential life lost, and productivity losses - United States, 2000-2004. Morbidity and Mortality Weekly Report, 57(45), 1226-1228.

Centers for Disease Control and Prevention. (2011). Vital signs: Asthma prevalence, disease characteristics, and self-management education - United States, 20012009. Morbidity and Mortality Weekly Report, 60(17), 547-552.

Cohen, M. A. (1998). The monetary value of saving a high-risk youth. Journal of Quantitative Criminology, 14(1), 5-33.

Cohen, M. A., \& Piquero, A. R. (2009). New evidence on the monetary value of saving a high-risk youth. Journal of Quantitative Criminology, 25(1), 25-49. http://dx.doi.org/10.1007/s10940-008-9057-3

Cohen, M., A., Piquero, A. R., \& Jennings, W. G. (2010). Estimating the costs of bad outcomes for at-risk youth and the benefits of early childhood interventions to reduce them. Criminal Justice Policy Review, 21(4), 391-434. http://dx.doi.org/10.1177/0887403409352896

Cohen, M. A., Rust, T. R., Steen, S., \& Tidd, S. T. (2004). Willingness-to-pay for crime control programs. Criminology, 42(1), 89-110. http://dx.doi.org/10.1111/j.1745-9125.2004.tb00514.x

Compton, W. M., Thomas, Y. F., Stinson, F. S., \& Grant, B. F. (2007). Prevalence, correlates, disability, and comorbidity of DSM-IV drug abuse and dependence in the United States: Results from the national epidemiologic survey on alcohol and related conditions. Archives of General Psychiatry, 64(5), 566-576. 
International Journal of Child, Youth and Family Studies (2014) 5(4): 588-608

In Harm's Way: A Special Issue on the Impacts and Costs of Witnessing Intimate

Partner Violence

Craig, W., Schumann, L., Petrunka, K., Khan, S., \& Peters, R. (2011). Government costs associated with delinquent trajectories. International Journal of Child, Youth and Family Studies, 2(1), 263-294.

Cromie, W. J. (2002, November 7). Long-term memory kicks in after age one. Harvard University Gazette.

Daley, M., Morin, C. M., LeBlanc, M., Gregoire, J., \& Savard, J. (2009). The economic burden of insomnia: Direct and indirect costs for individuals with insomnia syndrome, insomnia symptoms and good sleepers. Sleep, 32(1), 55-64.

Dauvergne, M., \& Johnson, H. (2001). Children witnessing family violence. Ottawa, ON: Statistics Canada.

DeLisi, M., \& Gatling, J. M. (2003). Who pays for a life of crime? An empirical assessment of the assorted victimization costs posed by career criminals. Criminal Justice Studies, 16(4), 283-293. http://dx.doi.org/10.1080/0888431032000183489

Finer, L. B., \& Zolna, M. R. (2011). Unintended pregnancy in the United States: Incidence and disparities, 2006. Contraception, 84(5), 478-485. http://dx.doi.org/10.1016/j.contraception.2011.07.013

Foster, E. M., Jones, D. E., \& Conduct Problems Prevention Research Group. (2005). The high costs of aggression: Public expenditures resulting from conduct disorder. American Journal of Public Health, 95(10), 1767. http://dx.doi.org/10.2105/ajph.2004.061424

Hanmer, J., Griffiths, S., \& Jerwood, D. (1999). Arresting evidence: Domestic violence and repeat victimization. Police Research Series, Paper 104. London: Home Office.

Hasin, D. S., Stinson, F. S., Ogburn, E., \& Grant, B. F. (2007). Prevalence, correlates, disability, and comorbidity of DSM-IV alcohol abuse and dependence in the United States. Archives of General Psychiatry, 64(7), 830-842. http://dx.doi.org/10.1001/archpsyc.64.7.830

Henggeler, S. W., \& Sheidow, A. J. (2003). Conduct disorder and delinquency. Journal of Marital and Family Therapy, 29(4), 505-522. http:/dx.doi.org/10.1111/j.1752-0606.2003.tb01692.x

Hillman, D. R., Murphy, A. S., Antic, R., \& Pezzullo, L. (2006). The economic cost of sleep disorders. Sleep, 29(3), 299-305.

Hoffman, S. D., \& Maynard, R. A. (Eds.). (2008). Kids having kids: Economic costs \& social consequences of teen pregnancy. Washington, DC: The Urban Institute. 
International Journal of Child, Youth and Family Studies (2014) 5(4): 588-608

In Harm's Way: A Special Issue on the Impacts and Costs of Witnessing Intimate

Partner Violence

Holzer, H. J., Whitmore Schanzenbach, D., Duncan, G. J., \& Ludwig, J. (2008). The economic costs of childhood poverty in the United States. Journal of Children and Poverty, 14(1), 41-61.http://dx.doi.org/10.1080/10796120701871280

Hossain, J. L., \& Shapiro, C. M. (2002). The prevalence, cost implications, and management of sleep disorders: An overview. Sleep and Breathing, 6(2), 85-102. http://dx.doi.org/10.1007/s11325-002-0085-1

Hotton, T. (2003). Childhood aggression and exposure to violence in the home. Ottawa, ON: Statistics Canada.

Jaffe, P., Wolfe, D. A., \& Wilson, S. K. (1990). Children of battered women. Newbury Park, CA: Sage Publications.

Johnson, H. (1996). Dangerous domains: Violence against women in Canada. Toronto: Nelson Canada.

Kernic, M. A., Holt, V. L., Wolf, M. E., McKnight, B., Huebner, C. E., \& Rivara, F. P. (2002). Academic and social health issues among children exposed to maternal intimate partner abuse. Archives of Pediatrics \& Adolescent Medicine, 156(6), 549-555. http://dx.doi.org/10.1001/archpedi.156.6.549

Kessler, R. C., Borges, G., \& Walters, E. E. (1999). Prevalence of and risk factors for lifetime suicide attempts in the National Comorbidity Survey. Archives of General Psychiatry, 56(7), 617-626. http://dx.doi.org/10.1001/archpsyc.56.7.617

Kwong, M. J., Bartholomew, K., Henderson, A. J. Z., \& Trinke, S. J. (2003). The intergenerational transmission of relationship violence. Journal of Family Psychology, 17(3), 288-301. http://dx.doi.org/10.1037/0893-3200.17.3.288

Lee, G. A., \& Forsythe, M. (2011). Is alcohol more dangerous than heroin? The physical, social and financial costs of alcohol. International Emergency Nursing, 19(3), 141-145. http://dx.doi.org/10.1016/j.ienj.2011.02.002

Lipton, R. B., Stewart, W. F., \& Scher, A. I. (2001). Epidemiology and economic impact of migraine. Current Medical Research and Opinion, 17(1), s4-s12. http///dx.doi.org/10.1185/0300799039117005

Martin, J. A., Kung, H. C., Mathews, T. J., Hoyert, D. L., Strobino, D. M., Guyer, B., \& Sutton, S. R. (2008). Annual summary of vital statistics: 2006. Pediatrics, 121(4), 788-801.

Mihorean, K. (2005). Trends in self-reported spousal violence. In K. Aucoin (Ed.), Family violence in Canada: A statistical profile, 2005. Ottawa, ON: Statistics Canada. 
International Journal of Child, Youth and Family Studies (2014) 5(4): 588-608

In Harm's Way: A Special Issue on the Impacts and Costs of Witnessing Intimate

Partner Violence

Moore, K. A., Harrison, M., Young, M. S., \& Ochshorn, E. (2008). A cognitive therapy treatment program for repeat DUI offenders. Journal of Criminal Justice, 36(6), 539-545. http://dx.doi.org/10.1016/j.jcrimjus.2008.09.004

Ohayon, M. M. (2002). Epidemiology of insomnia: What we know and what we still need to learn. Sleep Medicine Reviews, 6(2), 97-111. http://dx.doi.org/10.1053/smrv.2002.0186

Olesen, J., Gustavsson, A., Svensson, M., Wittchen, H.-U., \& Jonsson, B. (2012). The economic cost of brain disorders in Europe. European Journal of Neurology, 19(1), 155-162. http://dx.doi.org/10.1111/j.1468-1331.2011.03590.x

Park, D. E. (2010). Economic aspects of the development and prevention of criminality among children and youth: A sequel to the Kids ' $N$ Crime Report. Vancouver, BC: The Vancouver Board of Trade and Justice Institute of British Columbia.

Pradalier, A., Auray, J., Hasnaoui, A. E., Alzahouri, K., Dartigues, J., Duru, G., ... Gaudin, A. (2004). Economic impact of migraine headaches in France: Data from the GRIM2000 study. Pharmacoeconomics, 22(15), 985-999. http://dx.doi.org/10.2165/00019053-200422150-00003

Ramiro, L. S., Madrid, B. J., \& Brown, D. W. (2010). Adverse childhood experiences (ACE) and health-risk behaviors among adults in a developing country setting. Child Abuse \& Neglect, 34(11), 842-855. http://dx.doi.org/10.1016/j.chiabu.2010.02.012

Reeves, C., \& O’Leary-Kelly, A. M. (2007). The effects and costs of intimate partner violence for work organizations. Journal of Interpersonal Violence, 22(3), 327344. http://dx.doi.org/10.1177/0886260506295382

Reid, J. L., Hammond, D., Burkhalter, R., Rynard, V. L., \& Ahmed, R. (2013). Tobacco use in Canada: Patterns and trends, 2013 Edition. Waterloo, ON: Propel Centre for Population Health Impact, University of Waterloo.

Rehm, J., Baliunas, D., Brochu, S., Fischer, B., Gnam, W., Patra, J., ... Taylor, B. (2006). The costs of substance abuse in Canada 2002. Ottawa, ON: Canadian Centre on Substance Abuse.

Rivara, F. P., Anderson, M. L., Fishman, P., Bonomi, A. E., Reid, R. J., Carrell, D., \& Thompson, R. S. (2007). Healthcare utilization and costs for women with a history of intimate partner violence. American Journal of Preventive Medicine, 32(2), 89-96. http://dx.doi.org/10.1016/j.amepre.2006.10.001

Rosekind, M. R., Gregory, K. B., Mallis, M. M., Brandt, S. L., Seal, B., \& Lerner, D. (2010). The cost of poor sleep: Workplace productivity loss and associated costs. Journal of Occupational and Environmental Medicine, 52(1), 91-98. http://dx.doi.org/10.1097/jom.0b013e3181c78c30 
International Journal of Child, Youth and Family Studies (2014) 5(4): 588-608

In Harm's Way: A Special Issue on the Impacts and Costs of Witnessing Intimate

Partner Violence

Sacks, J. J., Roeber, J., Bouchery, E. E., Gonzales, K., Chaloupka, F. J. \& Brewer, R. D. (2013). State costs of excessive alcohol consumption, 2006. American Journal of Preventive Medicine, 45(4), 474-485. http://dx.doi.org/10.1016/j.amepre.2013.06.004

Scarborough, P., Bhatnagar, P., Wickramasinghe, K. K., Allender, S., Foster, C., \& Rayner, M. (2011). The economic burden of ill health due to diet, physical inactivity, smoking, alcohol and obesity in the UK: An update to 2006-07 NHS costs. Journal of Public Health, 33(4), 527-535. http://dx.doi.org/10.1093/pubmed/fdr033

Sinha, M. (2012). Family violence in Canada: A statistical profile, 2010. Ottawa, ON: Statistics Canada.

Sonfield, A., Kost, K., Gold, R. B., \& Finer, L. B. (2011). The public costs of births resulting from unintended pregnancies: National and state level estimates.

Perspectives on Sexual and Reproductive Health, 43(2), 94-102. http://dx.doi.org/10.1363/4309411

Statistics Canada. (2007). Family portrait: Continuity and change in Canadian families and households in 2006. Ottawa, ON: Author.

Statistics Canada. (2011). Family violence in Canada: A statistical profile. Ottawa, ON: Author.

Subramanian, S. V., Ackerson, L. K., Subramanyam, M. A., \& Wright, R. J. (2007). Domestic violence is associated with adult and childhood asthma prevalence in India. International Journal of Epidemiology, 36(3), 569-579. http://dx.doi.org/10.1093/ije/dym007

Trussel, J. (2007). The cost of unintended pregnancy in the United States. Contraception, 75(3), 168-170. http://dx.doi.org/10.1016/j.contraception.2006.11.009

van Dijk, J. J. M. (2001). Attitudes of victims and repeat victims toward the police: Results of the International Crime Victims Survey. Crime Prevention Studies, 12, 27-52.

Varcoe, C., Hankivsky, O., Ford-Gilboe, M., Wuest, J., Wilk, P., Hammerton, J., \& Campbell, J. (2011). Attributing selected costs to intimate partner violence in a sample of women who have left abusive partners: A social determinants of health approach. Canadian Public Policy, 37(3), 359-380. http:/dx.doi.org/10.1353/cpp.2011.0029

Weissman, M. M., Bland, R. C., Canino, G. J., Greenwald, S., Hwu, H. G., Joyce, P. R., ... Yeh, E. K. (1999). Prevalence of suicide ideation and suicide attempts in nine countries. Psychological Medicine, 29(1), 9-17.http://dx.doi.org/10.1017/s0033291798007867

Yang, B., \& Lester, D. (2007). Recalculating the economic cost of suicide. Death Studies, 31(4), 351-361. http://dx.doi.org/10.1080/07481180601187209 
International Journal of Child, Youth and Family Studies (2014) 5(4): 588-608

In Harm's Way: A Special Issue on the Impacts and Costs of Witnessing Intimate Partner Violence

Zhang, T., Hoddenbagh, J., McDonald, S., \& Scrim, K. (2012). An estimation of the economic impact of spousal violence in Canada, 2009. Ottawa, ON: Department of Justice, Canada.

Zielinski, D. (2009). Child maltreatment and adult socioeconomic well-being. Child Abuse \& Neglect, 33(10), 666-678.http://dx.doi.org/10.1016/j.chiabu.2009.09.001 